\title{
Teachers' Views on the Implementation of the English Language Proficiency Programme in Namibia
}

\author{
Elizabeth N. Ngololo ${ }^{1}$ \& Haaveshe Nekongo-Nielsen ${ }^{2}$ \\ ${ }^{1}$ Multi-disciplinary Research Centre, University of Namibia, Namibia \\ ${ }^{2}$ Office of Academic Affairs, University of Namibia, Namibia \\ Correspondence: Elizabeth N. Ngololo, Multi-disciplinary Research Centre, University of Namibia, P. O. Box \\ 60779, Katutura, Windhoek, Namibia. Tel: 264-81-122-9022. E-mail: engololo@unam.na
}

Received: May 15, $2017 \quad$ Accepted: June 19, $2017 \quad$ Online Published: October 28, 2017

doi:10.5539/ies.v10n11p155 URL: https://doi.org/10.5539/ies.v10n11p155

\begin{abstract}
The study explores teachers' views on the impact of the English Language Proficiency Programme in Namibian schools that was implemented over a period of five years, from 2011 to 2015. The program aimed at improving teachers' proficiency in English. The summative evaluation was conducted in 2016 in the following five (5) regions: Erongo, Hardap, Khomas, Ohangwena and Omusati, selected on the basis of the level of participation and accessibility. The evaluation focused on the following aspects of the project: program development, program implementation and administration as well as assessment of learning outcomes. The study followed a qualitative approach using document analysis to inform the development of evaluation instruments and a phenomenological design to assess teachers' lived experiences during program implementation. Data was collected through focus group discussions among teachers. The study established that teachers did not appreciate the program as it was ill-planned, irrelevant to their needs and disturbed their daily routines. Nevertheless, a few teachers embraced the program and reported positive benefits in terms of teachers' career development goals. The study recommends the revision of the program in terms of content and implementation procedures. In addition, teachers' support systems, learning materials and the mode of delivery need improvement to effectively enhance teaching and learning in Namibian schools.
\end{abstract}

Keywords: English language proficiency programme, ELPP, Namibian language policy, teachers' professional development, summative evaluation

\section{Introduction}

\subsection{The Problem}

After Namibia gained her independence in 1990, the Namibian Language Policy was adopted to establish English as an official language and the medium of instruction in Namibian schools. The development of the language policy took into account the fact that Namibia is a multilingual society with fourteen (14) written languages used in school, in addition to the Sign Language ((Education Management Information System (EMIS), 2015)). The country had adopted English as an official language to unite the Namibian people under one language (Harlech-Jones, 1990; Ministry of Basic Education and Culture (MBEC), 1993). The policy states that from Grades 1 to 3 children will be taught in Mother Tongue and from Grade 4 through Grade 12 all subjects will be taught in English (Ministry of Education, 1991). This policy statement was implemented even if teachers were not prepared fully to take on the task of using English in teaching. The sudden switch to English as a medium of instruction forced teachers to develop lessons, teach and interact in the language in which they were not fluent (Harlech-Jones, 1990).

\subsection{The Importance of the Problem}

In implementing the language policy, teachers encountered a number of challenges in classroom practice. Mostert et al. (2012) noted that in Namibia, teachers are expected to operate in the official language, even though they had limited exposure to English in their daily lives. The authors observed that some school principals are especially concerned about the language proficiency of teachers. These findings are in agreement with earlier studies conducted by the Ministry of Education In 2000 the Ministry of Education conducted research into the English Language of Teachers/Student Teachers and in 2001 the Feasibility Study on the English Language 
Proficiency of Namibian Teachers was carried out. The findings of the two studies revealed that teachers are not fluent in the language and the school environment is not conducive for learning English. Recent research continues to discover that teachers are not confident to teach in English, thereby affecting learners' performance negatively, especially in external examinations (Simasiku, Kasanda \& Smit, 2015). In addition, Olivier (2008) noted the lack of research to discover the specific language needs of teachers.

To guide the development of the program to address the gaps, an English language proficiency test was administered to teachers, country wide in 2010 . The purpose of the language proficiency test was to determine teachers' readiness for communicative role and their language ability in order to predict learners' future performance (Wolfaardt \& Schier, 2011). The proficiency test was administered to a sample size of 22, 399 of the 27, 000 teachers from public and private schools across "all 13 regions" (NSA, 2012, p. 19). The test results placed teachers' proficiency in English into four different levels in terms of competency: Pre-intermediate (35.76\%), Intermediate (42.99\%), Advance (19.59\%) and 1.66\% of the teachers were declared proficient (Fourie \& Kemanya, 2015). This outcome shows that a large number of teachers (78\%) have generally performed poorly. Fourie and Kemanya indicated that the low performance is attributed to lack of reading culture among teachers. Hence, teachers "expressed the urgent need of improving their own English Language Proficiency (ELP)" (Wolfaardt \& Schier, 2011. p. 6).

The findings of the 2000 and 2001 and subsequent studies were therefore used to inform the development of the English Language Proficiency Programme (ELPP). Accordingly, on the basis of the placement test, program study materials were developed into the three levels of proficiency, namely: Pre-intermediate, Intermediate and Advanced. The ELPP was then implemented country wide from 2011 to August 2015.

At the end it was thus thought useful to evaluate the program for purposes of determining the level of program effectiveness. The evaluation study was thus commissioned and carried out between 21 June and 29 July 2016. The summative evaluation was conducted with the belief that program evaluation is increasingly concerned about learning, empowering program participants and enabling transformation in the teaching field with an aim to improve and/or redesign the program (Stufflebeam, 2003).

\subsection{Relevant Scholarship}

It has been long recognized that teachers are the most important resource in schools and that they are critical in raising educational standards (Santiago \& Benavides, 2009). Yet, learning opportunities for teachers are "woefully inadequate to meet today's classroom demands... and less adequate in assisting them to meet the overwhelming challenges of their work" (Sparks, 2002 p. 14). Sparks further remarked that quite often educational staff development programs continue to leave teachers' knowledge and skills untouched and teachers are usually not given time nor support to effectively execute their duties. Consequently, researchers believe that improving effectiveness in teaching should be the aim of any teachers' professional development program (Mulkeen, 2005; Santiago \& Benavides, 2009; Samson \& Collins, 2012; Dearden, 2015).

Globally however, it has been noted that many teachers in non-native English speaking countries come to use English as a medium of instruction without a great deal of training and preparation, resulting in them facing a lot of challenges (Nha, \& Burns, 2014; O’Dowd, 2015, Lyamine \& Mlambo, 2016). As a result, English Language Proficiency Programs for teachers have been developed and implemented to prepare teachers improve their level of English (Samson \& Collins, 2012; Dearden, 2015). Such programs usually serve two purposes: (i) improve teachers' level of English proficiency; and (ii) ensure that teachers teach their subjects effectively, using English as a medium of instruction.

The importance of educational program evaluation is found to influence learning through empowering program participants and enabling transformation in the teaching field (Fullan, 1998). Coskun and Daloglu (2010) noted that much has not been done in evaluating English Teacher Education Programs. This is probably due to the fact that foreign language teachers' education is a recent development when compared to other areas of education. However, Coskun and Daloglu stress that a few attempts have been made to develop a model that could be used to evaluate such programs.

A few evaluation studies that were conducted found that teachers require a higher command of English to be able to use English as a medium of instruction (Nha \& Burns, 2014; O’Dowd, 2015). They also found that teachers were not effective in influencing the language abilities of their learners (Nha, \& Burns, 2014); but, there was a positive correlation between teachers' English proficiency and teacher motivation as well as classroom environment (Makewa, Role, \& Tuguta, 2013). Evaluation studies also established that English Proficiency Programs have been effective and successful in raising educational standards (Samson \& Collins, 2012). 
It has thus been recommended that courses to address teachers' deficiencies should be structured to meet the teachers' practical needs and should use more modern technologies (Coskun \& Daloglu, 2010). They further recommend regular evaluation of such programs for purposes of improving teachers' content knowledge and teaching skills or pedagogical approaches. In Namibia, generally, all subjects are taught through English making it worth exploring how teachers have experienced the acquisition of the English language skills through the ELPP

\subsection{Hypothesis and its Correspondence to Research Design}

The theoretical perspective of this study draws on the work of Stufflebeam (2003) regarding, the Context Input Processes and Products Model (CIPP) for evaluation studies. The CIPP stresses that context evaluations assess needs, problem and opportunities to help the participants' judge goals, priorities and outcomes and help decision makers define goals and priorities for improvement. According to the CIPP Model input evaluation methods assess alternative approaches, competing action plans, budgets for feasibility and potential cost effectiveness in achieving goals. Process evaluation methods assess the implementation of plans to help staff carry out activities and later help participants' judge program performance and interpret outcomes. Product evaluation methods on the other hand identify and assess outcomes - intended and unintended, short term and long term outcomes and ultimately help participants gauge the program's success in meeting targeted needs. CIPP evaluations are conducted to focus on program improvement. The CIPP Model requires an understanding of the context in which the program was developed and implemented (Stufflebeam, 2003).

The ELPP was developed in consideration of a number of factors and in line with the CIPP models' first requirement of context description. As described in Section 1.2 a number of studies confirmed that teachers lack proficiency in teaching in English language Harlech-Jones, 1990; Ministry of Basic Education, Sports and Culture, 2000; Ministry of Basic Education, Sports and Culture, 2001; Wolfaardt \& Schier, 2011; Mostert et al., 2015 ) and that there was insufficient information regarding the English language needs of teachers in the country (Olivier, 2008).

The framework in which the program was implemented enabled organizational and management structures to be established for effective operation. A three level administration and coordination structure was set up at national, regional and school levels. The ELPP was managed by the Project Steering Committee comprised of membership from key stakeholders, including the Ministry of Education, and the implementing agency and a teachers' union to review and approve the implementation plans, resourcing, timeline, scope, activities and other deliverables.

Furthermore, the ELPP had a three phase structural implementation levels at national, regional and school. Nationally, two program administrators were responsible for the overall administration and coordination. Regionally, there were area managers who liaised between the implementing agency and the schools, ensuring delivery of registration forms, learning materials, test papers and certificates as well as allocating venues and disseminate other information to schools. At the school level, principals, facilitators and tutors were appointed. Principals were tasked to facilitate the registration process, recruit suitable school facilitators, assist in recruiting qualified tutors, administer tests and encourage teachers to participate in the ELPP (Fourie \& Kemanya, n.d.). In turn, facilitators were responsible for the distribution of study materials, informing principals about progress and problems encountered by teachers. Cluster based tutors were recruited at two levels of the pre-intermediate and intermediate, to provide learning support; organize face-to-face sessions; and provide feedback to program administrators as per the reporting requirements. All of these role players were inducted into their tasks using a combination of strategies. Specifically, facilitators and tutors received extensive training in methods of supporting teachers and were provided with ample information in the form of a four units' manual. The focus on tutoring concentrated mainly on reading, writing, listening, speaking and language usage (Fourie \& Kemanya, n.d.).

\section{Method}

This section describes the methodology used to collect data on teachers' views regarding the ELPP design, development and implementation in the selected educational regions. Teachers were interviewed at schools, the natural setting of their employment, to determine the overall judgement about the effectiveness of the ELPP.

\subsection{Research Design}

The summative evaluation (ex post) study followed qualitative approaches of content analysis and phenomenology design. Content analysis was used to inform the development of evaluation instruments which were used to collect data through focus group discussions while phenomenology assessed the learning outcomes 
to determine the overall achievement of the program from teachers' perspectives. Qualitative data in summative evaluations typically add depth, detail, and nuance individualized outcomes and issue of quality in the program (Patton, 2002).

\subsection{Population of the Study}

The population of this study comprises of all 27,948 teachers in the fourteen (14) educational regions in Namibia (EMIS, 2015), who were employed by the Ministry of Education and Private Schools. The evaluation study comprised of teachers from five out of the 14 educational regions.

\subsection{Sampling Procedures}

Using the convenience sampling procedure the study regions of Erongo, Hardap, Khomas, Ohangwena and Omusati were selected on the basis of their level of participation and accessibility with regards to the vastness of the regions and distance between schools. Using a stratified sampling procedure for each region, six schools were selected based on the locality, whether rural or urban; school phases (i.e. primary, combined and secondary) and level of participation (low or high). Overall, a total of 40 focus groups, one group per school, comprising a minimum of six (6) to a maximum of ten (10) teachers were selected. The sample included teachers who participated in the ELPP and those who did not; teachers at all the proficiency levels (pre-intermediate, intermediate and advance) and teachers who had been declared proficient or exempted from participation.

\subsection{Data Collection Methods}

The methods employed to collect data included desk study in order to inform the evaluation instruments which primarily consisted of the interview guide used to collect data through focus group discussions. The desk study reviewed a number of articles and books on English proficiency and evaluation of educational programs to uncover key issues regarding the ELPP development, administration, implementation and impact. The focus group discussions were conducted to determine how teachers experienced the ELPP implementation. During the focus group discussions, a conducive environment of openness and trust was created to enable the participants express themselves freely and authentically (Potter, 2006). During the focus group discussions, teachers heard each other's responses and made additional comments beyond their own original responses as they heard what other teachers had to say. Thus, teachers' responses were negotiated and high quality data was obtained as participants considered their own views as well as views of their colleagues (Patton, 2002).

\subsection{Data Analysis}

The content analysis approach was used to identify coherent and important themes and patterns in the data. Data that addressed a particular evaluation question was grouped and then categorized into patterns and themes. The themes were categorized as follows: teachers' opinions on the marketing/publicity of the program; purposes and relevance of the program; development and design of the program; benefits of face-to-face sessions; suitability of content; usefulness of study materials; and the overall rating of the program. The evaluators recorded the program activities, collected data on participants' interactions and conversations as well as participants' intervention efforts and reactions. In addition, participants' experiences, how they viewed the program, what they did differently and their expectations for the future were analyzed (Patton, 2002).

\section{Results}

As described in Section 1.4 the study findings are presented and discussed within the framework of the CIPP Model themes of context, input, process and product.

\subsection{Context}

Teachers emphasized that the program was forced upon them to register, write the test and subsequently to participate. Teachers explained that they "were forced to participate in a program they did not understand" and therefore viewed the program as unnecessary and a hindrance to their daily routines. Accordingly, the majority of teachers alleged that school principals lured them to: participate and write the tests. The principals persuaded teachers by explaining to them that teachers were employees of the Ministry of Education and should not be influenced by external forces such as teachers' unions. Teachers in all regions wrote tests against their will and unprepared because they did not want to be seen by their principals as rebellions. As a result, most teachers failed to progress to the next level and remained at the same level of competency at least in the first year. However, over time, a number of teachers participated and progressed to higher levels with some exiting the program.

The evaluators discovered that most English subject teachers favored the program as they were appointed as tutors and facilitators. They strongly argued that teachers of other subjects could be more effective in their 
teaching if they were proficient in English. However, the non-English teachers did not like the fact that tutors were familiar faces, their own colleagues, and in some cases, teachers from the primary school phase. They questioned tutors' capabilities, asking “.....what would a teacher of English [as an ELPP tutor] with an output of $2 \%$ pass rate at national level contribute to the English proficiency of other teachers"? [A member of the Ohangwena Region Focus Group stated, June 2016].

\subsection{Input}

The design of the program took into consideration administrative structures, including program development and implementation. Teachers commended on the Program's design as it enabled participants to move from one level to another progressively. This was seen by many teachers as the strength of the program, resulting in them looking forward to taking the test as a challenge in the hope to pass with high grades and be declared proficient in English and subsequently exit the program.

Teachers remarked that the distance between schools and the tutorial venues in attending face-to-face sessions was overlooked during the design and development of the program. They also complained about the lack of: provision of refreshment, conduciveness of the tutorial venues as well as the schedule and timing of the tutorials. They however praised the program for an effective delivery system of study materials and tests to schools. In order to ensure effective teaching and learning, tutors were remunerated for their efforts. Additionally, tutors' participation in the program resulted in an unintended outcome of being promoted to senior position within the school system.

Teachers complained that the study materials content was pitched at a high level, beyond their capabilities and areas of interest. Particularly, primary school teachers and teachers of indigenous languages in secondary schools gave negative comments on topics covered in the program. Some teachers supported the program and argued it was suitable and useful in addressing teachers' needs for English proficiency. Some others remarked that 'if we are to teach English across the curriculum then it was important for non-English teachers to be proficient in the language of instruction'. They particularly found components of language usage (grammar), reading, general language usage, and writing (for administration, especially writing reports, minutes and memos) very well covered. Notably, some Mathematics teachers also embraced the program and saw its relevance to their daily use in and outside of the classroom. However, the same teachers were disappointed that the content was not always contextualized in their teaching fields and to the Namibian conditions, especially passages selected for reading and essay topics. Teachers, especially at primary school level demanded that the study materials be customized to their level, including more pictures and visual elements. Teachers at the advance level also noted that the study materials were pitched at a high level and some could not pass the test.

Contrary to what they studied in the ELPP, teachers felt that all tests were not appropriate; but then again too difficult at pre-intermediate and advance levels. Since most teachers at pre-intermediate level were mostly primary school teachers, they found the tests difficult. Furthermore, teachers questioned what was being tested, whether it was 'teachers' knowledge of certain topics' or 'language proficiency'. A few teachers further questioned the reliability of the test results due to the fact that they managed to progress to the next level 'without reading the study materials provided for the program'.

The listening component received the most criticism. Teachers disliked the accent of the reader on the CD because it was foreign, 'not Namibian'. This made it difficult for many participants to understand what was being said. Furthermore, participants found that the oral component did not receive sufficient attention in the program as it was not assessed, even though it was understood that 'teaching is speaking'. The evaluators nevertheless observed a positive attitude and a competitive spirit amongst science and mathematics teachers, especially when they progressed to the proficiency level.

Overall, the evaluators noticed that teachers found the study materials appropriate in addressing a variety of learning needs. A few teachers scanned through, mainly before the test, and also saw the usefulness of the study materials. Those who read and skimmed used the study materials as reference to their further studies and some gave it to their children at secondary schools as additional study materials. Nonetheless, color coding of the study materials caused stigma amongst participants. Many participants disliked the fact that learning materials had different colors for different levels. This was contrary to Program Administrators 'notion of confidentiality' regarding participants' proficiency status.

Marketing of the program emerged as one of the most significant determinant factor of the success of program implementation of this evaluation study. Most teachers stated that 'the program was not marketed very well' or perhaps the 'introduction did not happen correctly'. Teachers claimed that they first heard about the program through the media when the first placement test results leaked and described in the article entitled: " $98 \%$ of 
teachers not fluent in English" (Kisting, 2011, p.1). This resulted in teachers developing a negative attitude towards the program and reluctance to participate, concluding that the Ministry of Education has denigrated the profession of teachers in general and teachers' capabilities regarding teaching in English.

\subsection{Process}

The evaluators noticed that teaching sessions were poorly planned, organized and failed to meet teachers' demands. Teachers wanted more face-to-face sessions to be offered during week days other than on Saturdays when schools had sports activities and teachers had their community and family responsibilities to attend to. Teachers further demanded to have school-based tutors who would be consulted timely whenever a need arose. In fact, teachers claimed that it would be easy if each school arranged tutorial sessions as it suits them. Teachers provided three reasons why it was convenient for them to have school-based tutoring sessions: (i) less disruptions of their already agreed schedules at school level, (ii) solving transport problems of getting to the tutorial venues, and (iii) lack of refreshment provisions. During face-to-face sessions, tutors did not diversify their teaching methods, they mostly used 'chalk and talk'. For instance, teachers complained about the lack of visual materials and questioned why tutorials were not recorded and posted on the e-learning platforms. Young teachers especially preferred a blended learning approach of face-to-face and Information Communication Technologies (ICTs).

Teachers also commented on the logistical challenges of delivering study material and tests to the schools. Some teachers found that the procedure of delivering tests to the venues failed, resulting in some of them missing tests and failing to advance to the next level. This was evident in schools where neither the principals had interest nor participated in the program. In some cases, e administrators and/or area managers had made no prior arrangement to deliver the study materials and or the tests.

\subsection{Product}

Some teachers expressed that overall the program was a success, especially those who progressed from one level to another. These teachers and their principals noted that there was an improvement in the way they spoke English (both in class and during staff meetings), wrote communiques and lesson plans and conducted devotions in English. Principals noted that teachers tended to correct themselves and each other when speaking. Furthermore, the results showed that the ascending levels created competitiveness amongst teachers, wanting to exit the program. Yet, the majority of teachers at schools with a low participation rate did not see the worthiness of the program, as they did not actively participate due to lack of understanding the purpose of the program. These teachers developed a negative attitude early on, at the beginning of the program. In addition, other impediments such as the negative publicity of the program through the media, delayed test results and the stigma attached to proficiency levels, especially the color coded pre-intermediate study materials, affected teachers learning. Those who failed to progress and stagnated at the same level saw the program as irrelevant and interfering with their routines. These sentiments were especially expressed by older teachers, lower primary school teachers, teachers of indigenous languages and non-English teachers.

\section{Discussion}

In this study, evaluation is concerned about improving the quality of service provision in the classroom. The design of the program therefore looked into administrative structures and the organization of implementation processes at the different levels of the education system. Farsi and Sharif (2014) are of the opinion that the manner in which the program is organized may lead to desired outcomes. Evaluators noted that no monitoring mechanisms were included in the program design; as such shortcomings identified in the implementation process were not attended to timely.

This study, among other things, established that teachers did not like the fact that the participation and taking tests was forced upon them. They further conveyed their frustrations with principals luring them into participating behind claims that 'teachers were employees of the Ministry of Education and should not be influenced by external forces such as teachers' unions'. Consequently, teachers participated for the sake of pleasing their supervisors' (principals') and developed a negative attitude towards the program. In this regard, teachers needed motivation and a conducive environment to enhance learning (Makewa, Role, \& Tuguta, 2013). In addition, teachers needed to understand the purpose of the program for them to participate freely. Wayne, Yoon, $\mathrm{Zu}$, Cronen, and Garet (2008) argued that for a teachers' professional development program to be successful, its purpose must be aligned with the intended outcomes.

On the other hand, the study established that teachers' participation levels were in turn influenced by the principals' participation. If the principals had a negative attitude towards the program or had failed to grasp the 
importance of the program, it negatively affected the program implementation at school level. This scenario created an unpleasant environment that caused ineffective program implementation. This is in support of Blase and Blase (1999) who concluded that principals" positive and open reinforcement has an "enhancing effects" (p. 137) on teachers' participation in professional development programs. Moreover, when change is tempted under such circumstances it results in defensiveness, superficiality or at best short lived pockets of success (Fullan, 1998, p. 3). In this study, while most teachers participated, only some exited the programme.

The study findings further showed that confidentiality of the test results and all other assessments as well as the color coding of study materials contributed to teachers withdrawing as a result of lack of interest in the program. Additionally, some teachers reported to never have been received their marks till the end of the program. Teachers recommended administrative structures to be revised, with clear reporting lines at school level and a management information system developed to trace teachers after they have moved schools. Mulkeen (2005) asserts that teachers' hiring system in vast countries proved difficult to manage. In Malawi for example, after deployment, teachers could easily request for transfer to other areas of choice without any formal data capturing. Lack of data may influence the integrity of the information (Mulkeen, 2005) and as proved in the ELPP case, the administrative system was inefficient to handle teachers mobility as traceability proved difficult.

Additionally, findings indicated that the manner in which the marketing of the program was executed negated teachers' professional values. In broadcasting the program to the public, the newspapers described the Namibian teachers as unable to speak, read and write, and therefore not suitable to teach in English. Some teachers felt humiliated and withdrew their participation while others developed a negative attitude towards the program. When teachers' professional integrity is questioned, they tend to doubt the authenticity of the program, and they regard it with contempt (Hess, 2013). Moreover, Fullan (1998) is of the opinion that "the collaborative process involving teachers and administrators... seem to have the potential to make lasting and meaningful changes" in schools (p.80). In essence, teachers needed to find a platform where they could raise their concerns to be considered while continuing to participate in the program.

Teachers had also questioned the delivery methods used, arguing that they are full time employees but they were expected to carry and read volumes of print materials. Teachers were not consulted on the preferred delivery method (Wolfaardt \& Schier, 2011). Some, especially, the young teachers preferred a blended mode, learning using both videos and print materials. These finding support those of Coskun and Daloglu, 2010 where teachers demanded useful digitized courses that are practical and oriented to their needs. For example, the lower primary school teachers demanded study materials to be customized to their level, including more pictures and visual elements.

Most teachers reported that Intermediate or mid-term evaluation of the program was not conducted to ensure that deficiencies were addressed on time. It is emphasized that models of evaluation of English language programs was almost non-existent and that this discipline has not been pursued by many researchers (Coskun \& Daloglu, 2010). Assessment of such programs would help in the improvement of identifying alternative approaches, appropriate action plans in achieving the program's goals timely and effectively (Stufflebeam, 2003). On the other hand, DeMonte (2013) advised that follow up and continuous feedback is necessary for high quality professional development program for teachers.

\section{Conclusion}

In this paper, evaluation is concerned about improving the quality of service provision in the classroom. The study concludes that the English Language Proficiency Programme was not popular amongst teachers. Teachers, especially those teaching other subjects other than the English language felt that the program was a waste of time as it did not address their practical needs. Primary school teachers challenged the program's relevance to their needs since they are required to use indigenous languages as medium of instruction. Teachers misunderstood the aim of the program as an improvement in the medium of instruction rather than proficiency in their subject matter. However, some teachers, especially the older ones commented positively about the program and they claimed to have improved in speaking and writing skills from the contact sessions.

Many teachers dropped out as a result of negative publicity of the initial outcome of the survey. A few challenges were recorded on ineffective logistical procedures, administration of teachers' records and lack of inter-mediate evaluation processes which if addressed properly, could improve the implementation process. Despite the fact that this program was necessary for quality enhancement in the education system, teachers did not value it, resulting in the program not achieving its objective of 'improving teachers' proficiency in English'.

This evaluation study therefore recommends that the Ministry of Education and its stakeholders need to pay special attention to the following: 
(i) The program should be revised in terms of administrative structures with clear reporting lines at school level;

(ii) Teachers should be consulted for their input in the design of the program;

(iii) The program must be made relevant to teachers' needs in terms of content and pedagogical approaches, including a blended mode of delivery to also cater for teachers in the rural areas;

(iv) The program becomes part of the existing Continuous Professional Development (CPD) Program structures with built in self-evaluation mechanisms to be employed at intervals.

(v) A management information system must be developed to enable traceability of teachers after they have transferred schools.

\section{References}

Blase, J., \& Blase, J. (1999). Effective instructional leadership: Teachers' perspectives on how principals promote teaching and learning in schools. Journal of Educational Administration, 38(3), 130-141.

Coskun, A., \& Daloglu, A. (2010). Evaluating an English language teacher education program through Peacock's Model. Australian Journal of Teacher Education, 35(6), 24-42. https://doi.org/10.14221/ajte.2010v35n6.2

Dearden, J. (2015). English as a medium of instruction: A growing global phenomenon. A British Council Report in collaboration with the University of Oxford. Retrieved from https://www.britishcouncil.org/sites/default/files/e484_emi_-_cover_option_3_final_web.pdf

Education Management Information System. (2015). Education Statistics. Windhoek: Ministry of Education, Arts and Culture.

Elyssa, T., \& Steenkamp, J. (2012). Report on the Findings of the English Language Diagnostic Placement Test. UNAM, Windhoek: English Language Proficiency Programme.

Farsi, M., \& Sharif, M. (2014). Stufflebeam's CIPP Model \& Program Theory: A systematic review. International Language Learning and Applied Linguistics World, 6(3), 400-406.

Fourie, G., \& Kemanya, E. (2016). English Language Proficiency Programme: End of Project Report. Windhoek: UNAM

Fullan, M. (1998). Change forces: Probing the depths of educational reform. London: The Farmer.

Harlech-Jones, B. (1990). Language and the Constitution. Facetten, 9(2), 21-25.

Hess, F. (2013). "More PD': The easy (But Ineffectual) Answer”. Rick Hess Staright Up Blog, Retrieved from http://blogs.edweeks.org/edweek/rick_hess_straight_up/2013/02/more_pd_theeasy_but_ineffectual_answer. $\mathrm{html}$ ?utm_source $=$ feedburner\&utm_medium $=$ feed\&utm_campaign $=\overline{F e e d} \% 3 \mathrm{~A}+\mathrm{RickHessStraightUp}+\overline{\mathrm{p}} \% 28$ Rick + Hess + Straight + Up $\% 29$

Kisting, D. (2011, November 09). 98\% of teachers not fluent in English. The Namibian Newspaper, p. 1. Retrieved from http://www.namibian.com.na/index.php?id=87893\&page=archive-read

Konstantinos, A., \& Efrosini, K. (2003). Programme Evaluation Methodologies, a Comparative Assessment. Discussion Paper Series, 9(17), 387-404.

Lyamine, Y., \& Mlambo, N. (2016). Opportunities granted or denied: An analysis of teachers' implementation of English language syllabus' learning objectives and the fate of Grade 10 ESL learners at public schools in Windhoek. Journal for Studies in Humanities and Social Sciences, 5(2), 50-65.

Makewa, L. N., Role, E., \& Tuguta, E. (2013). Students' perceived level of English proficiency in secondary schools in Dodoma, Tanzania. International Journal of Instruction, 6(2), 35-52.

Ministry of Basic Education, Sports and Culture. (2000). English Language Proficiency of Namibian Teachers: Report on Research into: English Language Proficiency of Teachers/Student teachers and Basic Education Principals and Teachers' Perceptions of the Use of English in Namibian Schools. Windhoek, Namibia.

Ministry of Basic Education, Sports and Culture. (2001). Feasibility Study on the English Language Proficiency of Namibian Teachers. Windhoek, Namibia.

Ministry of Basic Education. (1993). Towards Education for All: a development brief for Education, Culture and Training. Windhoek: Gamsberg

Mostert, M. L., Hamunyela, M., Kasanda, C., Smit, T. C., Kangira, J., Zimba, R. F., . . Veii, K. R-H. (2012). Views and preferences of parents, teachers and principals on the implementation of the language policy in 
primary schools in Namibia: An explorative study in the Khomas region. Journal of Studies in Humanities and Social Sciences, 1(2), 167-178.

Mulkeen, A. (2005). Teachers for Rural Schools: A challenge for Africa. Ministerial Seminar on Education for Rural People in Africa: Policy Lessons, Options and Priorities, 7-9 September 2005, Ethiopia.

Nha, T. T. V., \& Burns, A. (2014). English as a medium of instruction: Challenges for Vietnamese tertiary lecturers. The Journal of Asia TEFL, 11(3), 1-31.

O'Dowd, R. (2015). The Training and accreditation of teachers for English medium instruction: A survey of European universities. Retrieved from http://s3.amazonaws.com/academia.edu.documents/37757700/EMI Survey_Report_ODowd.pdf?AWSAccessKeyId=AKIAIWOWYYGZ2Y53UL3A\&Expires=1489296096\& Signature=UPRzfsP2cr9u7ZX2yBTlrCLZj8c\%3D\&response-content-disposition=inline $\% 3 \mathrm{~B} \% 20$ filename \%3DThe_Training_and_Accreditation_of_Teache.pdf

Olivier, C. E. (2008). The oral proficiency of ESL teacher trainees in different discourse domains. Retrieved from https://repository.unam.edu.na/.../Olivier_The\%20oral\%20proficiency_2008.PDF?...1

Patton, M. Q. (2002). Qualitative Research and Evaluation Methods (3rd ed.). Thousand Oaks: Sage Publication.

Potter, C. (2006). Programme evaluation. In M. T. Blanche, K. Durreim, \& D. Painter (Eds), Research in Practice: applied methods for the social sciences (2nd ed.). Cape Town: Paarl Print.

Samson, J. F., \& Collins, B. A. (2012). Preparing all teachers to meet the needs of English Language learners: Applying research to policy and practice for teacher effectiveness. Center for American Progress. Retrieved from http://files.eric.ed.gov/fulltext/ED535608.pdf Accessed: 11 March 2017

Santiago, P., \& Benavides, F. (2009). Teacher evaluation: A conceptual framework and examples of country practices. Part of the OECD Review on Evaluation and Assessment Frameworks for Improving School Outcomes. Brussels: Organization for Economic Co-operation and Development (OECD).

Simasiku, L., Kasanda, C., \& Smit, T. (2015). Teaching Subjects Matters through English as the Medium of Instruction in the Namibian English Second Language Classroom. European Scientific. Journal for Studies in Humanities and Social Sciences (Special Edition), 1, 1857-7881.

Sparks, D. (2002). Designing powerful professional development for teachers and principals. Oxford, OH: National Staff Development Council.

Stufflebeam, D. L., McKee, H., \& McKee, B. (2003). The CIPP Model for Evaluation: an update, a review of the model's development and a checklist to guide implementation. A paper presented at the 2003 Annual Conference of the Oregon Program Evaluators Network (OPEN). Portland, Oregon.

The Namibian Newspaper. (2011). 98\% of teachers not fluent in English. Retrieved from http://www.namibian.com.na/index.php?id=87893\&page=archive-read

Wayne, A. J., Yoon, K. S., Zu, P., Cronen, S., \& Garet, M. S. (2008). Experimenting with teacher professional development: Motives and methods. Educational Researcher, 37(8), 469-479. https://doi.org/10.3102/0013189X08327154

Wolfaardt, D., \& Schier, C. (2011). Report on the Findings of the Needs Assessment Survey. Windhoek: Ministry of Education.

\section{Copyrights}

Copyright for this article is retained by the author(s), with first publication rights granted to the journal.

This is an open-access article distributed under the terms and conditions of the Creative Commons Attribution license (http://creativecommons.org/licenses/by/4.0/). 